\title{
Motivational values and gendered research performance
}

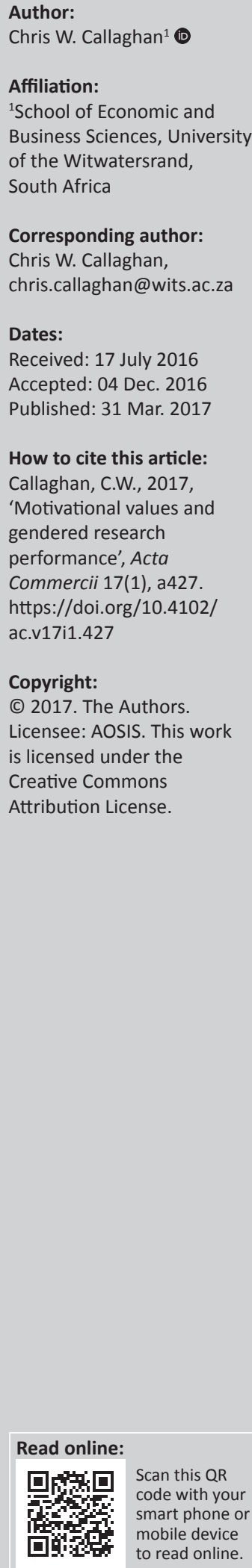

Orientation: Given theory offered by Kuhn and Lakatos that predicts academic research can be non-innovative, this research sought to test the extent to which the motivational values of highly productive researchers are innovative.

Research purpose: The aim of the research was to test theory predicting the structure of motivational values of academics in the South African university context.

Motivation for the study: The study was motivated by a lack of knowledge about whether innovative and self-transcendence (the prioritisation of the needs of others) values characterise highly productive researchers.

Research design, approach and method: A large South African university was sampled. Multiple linear regression and structural equation modelling techniques were applied.

Main findings: Findings indicate that non-innovative and gendered motivational values of security (sensitivity to uncertainty and safety issues) are associated with higher productivity. However, hedonism (self-oriented) and benevolence (self-transcendent) values are both found to be negatively associated with research productivity.

Practical/managerial implications: Supporting Kuhn's perspective, innovative values such as self-direction are not found to be related to research productivity.

Contribution/value-add: This study provides evidence in support of theory which predicts that academic research might not be motivated by innovative values.

\section{Introduction}

Individual basic values theory, also termed Schwartz's motivational values theory (Ross, Schwartz \& Surkiss 1999; Schwartz 1992, 1996, 2007; Schwartz \& Boehnke 2004), predicts human values form a structure of 10 values, themselves located within four overarching 'higher order' value types, a structure found across cultures (Schwartz \& Bardi 2001). According to this body of literature, human motivational values are important in that different motivational values configurations drive different human behaviours. Work behaviours, and different dimensions of job performance, are no less a function of motivational values and behaviours associated with these values. However, despite much management literature relating to performance across contexts, little is known of the motivational structure of highly productive researchers in the South African university context.

Other longstanding theory predicts that high performance in other contexts such as business can be related to a need for power or achievement (McClelland 1961; Winter 1973) which are essentially self-oriented values (Schwartz 2007). These self-oriented values form one axis of the Schwartz (2007) theoretical continuum, as does one other related to innovativeness. These are considered the primary two axes of Schwartz's (2007) values theory, which is considered a 'comprehensive' theory of values, incorporating all human values into an oppositional framework. Longstanding theory development around the innovativeness of academic research also reflects a tension, with theorists such as Kuhn (1970) and Lakatos (1970) questioning the inherent innovativeness of scientific research itself. This study, therefore, sought to investigate, firstly, the extent to which highly research productive individuals are primarily motivated by selfish, or self-oriented, values and, secondly, the extent to which they are motivated by innovative versus non-innovative values, as well as the extent to which these relationships are gendered.

Generating high research output, or research productivity, however, may differ substantively as a dimension of job performance from other organisational contexts with high executive 
remuneration (Massie, Collier \& Crotty 2014) that can be explicitly linked to performance. Academics, however, may be motivated by other factors not related to remuneration and because individual variability of values, or different configurations of values between individuals, has been found to predict individual differences in behaviour (Schwartz \& Bardi 2001), research productivity is taken to be no different. Arguably, knowledge of motivational values of highly productive researchers in this context is important, for the following reasons.

Firstly, this research is important for management of research contexts and management support for academics. Given academic work differs substantively from for-profit contexts of performance, in which performance can be linked to remuneration (Bussin \& Modau 2015), it is not clear how motivational values are associated with higher performance in academic contexts. Lack of knowledge of motivation values of highly productive research employees might also contribute to a lack of knowledge of retention preferences and perceived organisational support (Smit, Stanz \& Bussin 2015) and have implications for work engagement, turnover intentions (Takawira, Coetzee \& Schreuder 2014), subjective well-being, burnout and job satisfaction over time (Hansen, Buitendach \& Kanengoni 2015). Motivational values might signal potential for perceptions in working contexts to be disproportionately sensitive to different contextual or environmental characteristics. Further, knowledge of gender differences in motivational values and their contributions to job performance is considered particularly important in the South African developing country, context (Botha \& Cronjé 2015; Chinyamurindi 2016), with its history of gender and racial inequality and discrimination.

Secondly, given seminal concerns around fundamental lack of innovativeness of academic research itself (Kuhn 1970; Lakatos 1970; Latour 2000), and amidst much controversy around different assumptions and paradigms of academic research (Burrell \& Morgan 1979; Lewis \& Grimes 1999; Willmott 1993), what is lacking is knowledge of how important innovativeness is as a motivational value for highly productive researchers.

Thirdly, this research is important due to contextual imperatives. In a developing country context characterised by high youth unemployment (Mtembu \& Govender 2015) and even potential graduate unemployment (Oluwajodu et al. 2015), generational skills transfer is particularly important, and retention (Makhuzeni \& Barkhuizen 2015) of skilled educational staff is considered particularly important in this context. Losing such staff to other institutions or countries can be problematic for the development of other staff and students, as supervision and teaching contributions of these individuals due to their relatively high employability (Coetzee, Ferreira \& Potgieter 2015) and professional competencies (Schutte, Barkhuizen \& Van der Sluis 2015) can be particularly important assets for higher education institutions in a developing country, nested as it is within a global academic system competing for scarce academic talent and institutional capital. Having outlined the research and having discussed its contribution to the literature, its theoretical framework is now introduced, and hypotheses are derived for testing.

\section{Theory and hypotheses}

Schwartz's motivation value theory is used as a theoretical frame in this research as it is a comprehensive (incorporates all human values) values theory and also because it samples human values at the individual level of analysis. While much work has been done on values at the cultural, or group, level, this theory incorporates biological and social aspects of values into an extensive framework, useful for predicting human behaviour, including in contexts of job performance. In terms of the relationship between individual values and group, or aggregate level values, Schwartz (1994:22/23) offers the following perspective:

Is this set of ten value types exhaustive of all the main types recognized in different cultures? This question cannot be answered definitively... One assertion can be made. It is possible to classify virtually all the items found in lists of specific values from different cultures into one of these ten motivational types of goals.

Schwartz's (1994) individual values are associated with motivational goals, and are also derived, or have an origin in, biological and social needs. It is in the explicit integration of the biological and social aspects of motivations that these values contribute an understanding of individual level values. Whereas GLOBE cultural values theory (House et al. 2004) and Hofstede's (1980) culture theory represent a factor analytic cluster of universal values that manifest at aggregated levels, basic individual values represent a cluster of values according to a structure of human motivations, or goals (Schwartz 1994).

GLOBE, Hofstede and Schwartz values theories nevertheless all claim to be able to classify all human values types within their typologies, which are therefore considered comprehensive. The primary difference between Schwartz's (2007) theory and those of Hofstede (1980) and the GLOBE studies (Callaghan 2013) is that it incorporates biological, psychological and social aspects of motivational goals and therefore, comprehensively represents individual values, whereas the latter two cultural values theories are premised at the group level, with a focus on values shared by groups.

Rokeach and Ball-Rokeach (1989:775) stress that 'concepts of value and value systems are among the very few social psychological concepts that have been successfully employed across all social science disciplines'. The 10 values dimensions offered by Schwartz's values theory are motivationally distinct, in that they are underpinned by (1) biological requirements, (2) coordinative social requirements and (3) survival and welfare requirements (Schwartz 1992). The theory postulates that 'groups and individuals represent these requirements cognitively, as specific values about 
which they communicate in order to coordinate with others in pursuing the goals that are important for them' (Schwartz \& Boehnke 2004:234).

It is where conflict occurs between values that values become activated and are actively used as guiding principles (Schwartz 1992). Human behaviour typically follows 'habitual, scripted responses', yet values activation results in the active guidance of behaviour by values, which is aligned with the value or values that dominate such an internal contest of values (Schwartz 1996:121). This structure of values, however, is not static, but dynamic, where actions 'taken in pursuit of each type of values have psychological, practical, and social consequences that may conflict with or may be compatible with the pursuit of other value types' (Schwartz 1996:122). Knowledge of values effects is particularly important in a South African academic context facing increasing teaching loads and pressure to publish research (Callaghan 2015, 2016). The structure of values is now considered.

\section{Structure of values}

Basic values are theoretically ascribed a structure (similarity or dissimilarity of values with each other) and a content (the range of identified values) (Schwartz \& Boehnke 2004). Schwartz values theory postulates that 10 basic values are found in all societal contexts and that the structure of these values takes the form of a quasi-circumplex structure (Figure 1) that arises from an underpinning match, or mismatch, between their underlying motivational goals (Schwartz \& Boehnke 2004). Schwartz and Boehnke (2004) found, using two sets of 23 samples from 27 countries $(n=10857)$, that confirmatory factor analysis supported these 10 basic values, and their structure as a motivational continuum.

\section{Higher order values types}

As shown in Figure 1, these 10 basic values converge into four universal 'higher order' values types, which are

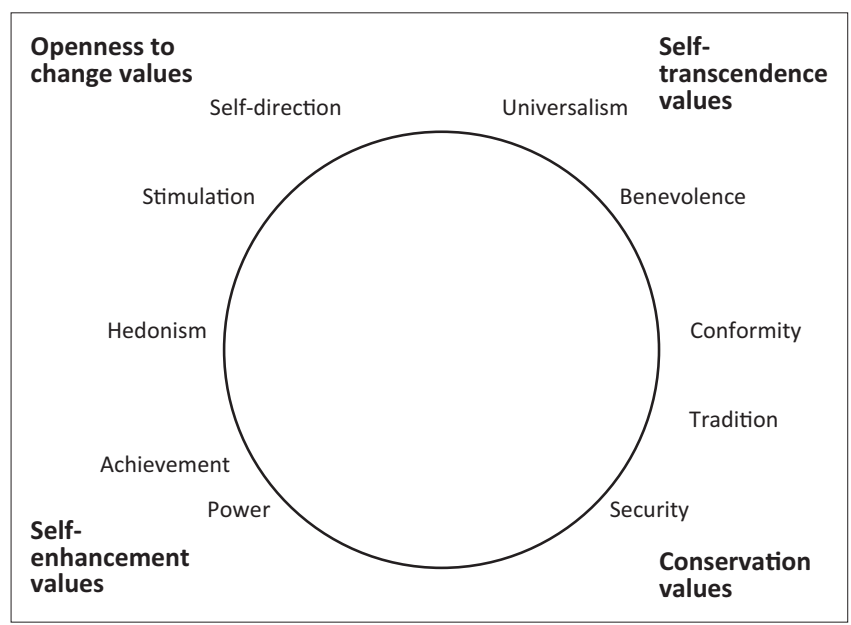

Source: Schwartz and Boehnke 2004:239

FIGURE 1: The Schwartz values theoretical circumplex structure. characterised by a fundamental tension: between Openness to change values and Conservation values, and between Self-enhancement values and Self-transcendence values (Schwartz \& Boehnke 2004). These four higher order types form a structure at polar points to the circumplex structure (Schwartz \& Boehnke 2004).

The four higher order types are: (1) Openness to change, which is closely associated with Self-direction and Stimulation values, (2) Self-enhancement, which is closely associated with Hedonism, Achievement and Power values, (3) Conservation, which is associated with Security, Conformity and Tradition values, and (4) Self-transcendence, which is associated with Benevolence and Universalism values (Schwartz \& Boehnke 2004). These value dimensions are each considered as follows.

\section{Openness to change values}

Self-direction values are associated with 'independent thought and action-choosing, creating, exploring', and with motivational goals associated with 'creativity, freedom, [being] independent, choosing [one's] own goals' and curiosity (Schwartz \& Boehnke 2004:239). Self-direction, therefore, is represented by independence or autonomy. SelfDirection values derive from goals which arise from the needs of an individual as a biological organism and also from the requirements of coordinated social interaction (Schwartz 1994). Self-direction, achievement and power values share an individualistic, or autonomous, aspect. However, whereas achievement and power values relate to the goals of the prioritisation of the individual over others, self-direction relates to the goal of independent thought for its own sake (Schwartz \& Boehnke 2004).

Stimulation values represent excitement, 'novelty, and challenge in life' (Schwartz \& Boehnke 2004). These values are related to motivational goals associated with daring, a varied life and having an exciting life (Schwartz 1996:122). Stimulation values are associated with goals that derive from the individual needs of individuals as biological organisms, rather than the requirements of coordinated social interaction or the smooth functioning and survival of groups (Schwartz 1994). Stimulation values, together with hedonism values, are the only values that have a biological origin, with no interaction or group source for the goals of these values (Schwartz 1994).

In terms of values constraints to research progression, Kuhn (1970) has argued that shared values of scientists are a primary constraint to the innovative progress of science. Further, Lakatos (1970) in seminal work has also questioned innovativeness of science, using examples of how core theoretical assumptions associated with Newtonian physics were maintained in the face of new discoveries. Given these seminal perspectives questioning inherent innovativeness of the academic process, what is not clear is how innovative are the values motivating highly productive researchers. However, given knowledge creation as the fundamental 
aspect of research, implying new knowledge, or innovative knowledge creation, Hypothesis $a$ is derived: that openness to change values are positively associated with research productivity.

\section{Self-enhancement values}

Hedonism values, achievement values and power values make up the higher order value set of self-enhancement values (Schwartz \& Boehnke 2004). Self-enhancement values motivate people to prioritise their own interests over the interests of others. Power and achievement values 'both emphasise social superiority and esteem' (Schwartz 1996:123). Both achievement and power values, according to Schwartz (1992), are associated with social esteem. Achievement values, however, are associated with striving to demonstrate competence, and power values are associated more with abstract outcomes related to status in social relations (Schwartz 1992). Achievement values are associated with individual action, or individual striving, while power values are associated with the hierarchical differentiation of societal relations (Schwartz 2007).

Hedonism values are adjacent in the structure of values to stimulation values (Schwartz 1994). Hedonism values are defined as being associated with pleasure 'and sensuous gratification for oneself', and associated with motivational goals of pleasure and the enjoyment of life (Schwartz 1996:122). Hedonism and stimulation values are both associated with a 'desire for affectively pleasant arousal' (Schwartz 1994:24). Hedonism values are also, in the same way as stimulation values, associated with goals that derive from the individual needs of individuals as biological organisms, rather than requirements of coordinated social interaction or the smooth functioning and survival of groups (Schwartz 1994). Individuals that are able to subordinate biologically oriented goal-related values such as hedonism to work tasks that are relatively 'less pleasurable' will be expected to have a greater tolerance for work that might offer less immediate gratification. If research work is less 'pleasurable' than other tasks, it is expected that hedonism values are negatively related to research productivity (Hypothesis $b$ ).

Hedonism and achievement values, which are adjacent to each other in the circumplex structure of values, are both associated with a 'focus on self-centred satisfaction' (Schwartz 1994:24). Achievement values are defined as being associated with personal 'success through demonstrating competence according to social standards' and motivational goals related to being 'successful, capable, ambitious and influential' (Schwartz 1996:122). Achievement values are associated with goals that are derived from interaction needs, or the requirements of coordinated social interaction, and also group needs, or the requirements for smooth functioning and survival of groups (Schwartz 2007). Achievement values, therefore, are an important aspect of work that relates to the social context. Achievement values and power values both emphasise social superiority and esteem (Schwartz 1994). However, despite certain commonalities, achievement values differ significantly from power values.
McClelland (1961) found that businesspeople were typically high in a need for achievement, particularly entrepreneurs and innovators. According to Winter (1973), however, 'businessmen' or business managers who are primarily concerned with coordination and control of business functions are expected to have a higher need for power than business managers who are more concerned with entrepreneurship and innovation. Therefore, the larger the bureaucratic organisation, the more opportunities might exist for the individual with a high need for power (Winter 1973).

Power values are defined as a motivational type of value associated with 'social status and prestige, control or dominance over people and resources' and that has goals associated with social power, authority and wealth (Schwartz 1996:122). Power values, like achievement values, are associated with goals that derive from interaction needs, or the requirements of coordinated social interaction, and also group needs, or the requirements for smooth functioning and survival of groups (Schwartz 1994). Given research productivity lacks individual incentivisation in the same way as performance in for-profit firms, and on the basis of discussions above, Hypothesis $c$ is proposed: that self-enhancement values are negatively associated with research productivity.

\section{Conservation values}

Security, conformity and tradition values make up the higher order conservation values type (Schwartz \& Boehnke 2004). Security values are associated with safety, 'harmony and stability of society, of relationships, and of self', and with motivational goals related to family security, national security, social order, cleanliness and the reciprocation of favours (Schwartz 1996:221). The motivational goals of security values derive from organismic needs (the 'needs of individuals as biological organisms'), interaction needs (the 'universal requisites of coordinated social interaction), and group needs (the 'universal requirements for smooth functioning and survival of groups') (Schwartz 1994:22).

Security values, together with benevolence values, are the only two values orientations that derive from all three of these types of origins. Both security and tradition values 'stress preserving existing social arrangements to give certainty to life', and both security and power values 'stress avoiding or overcoming the threat of uncertainties by controlling relationships and resources' (Schwartz 1994:25).

Conformity values derive from the 'prerequisite of smooth interaction and of group survival' (Schwartz 1996:122). Conformity values are associated with restraint 'of actions, inclinations, and impulses likely to upset or harm others and violate social expectations or norms', and also with motivational values related to politeness, obedience, self-discipline and honouring parents and elders. Both benevolence values and conformity values are associated with 'normative behaviour that promotes close relationships' 
(Schwartz 1994:25). Conformity goals are derived from interaction needs that support coordinated social interaction, and group needs that relate to the functioning and survival of groups (Schwartz 1994). Due to the focus of conformity values on the status quo rather than on change and innovativeness, it is predicted that conformity values are negatively associated with research productivity (Hypothesis $d$ ).

Tradition values relate to respect, 'commitment, and acceptance of the customs and ideas that traditional culture or religion provide' and are related to motivational goals of humility, devotion and acceptance of one's 'portion in life' (Schwartz 1994:22). These motivational goals, in turn, derive from group needs, or the needs for the smooth functioning and survival of groups (Schwartz 2007). The origin of these values does not relate to biological needs, or to interaction needs for coordinated social interaction (Schwartz 1994).

Benevolence and tradition values both 'promote devotion to one's ingroup' (Schwartz 1994:25). Tradition and conformity values share an aspect of subordination of the self to 'socially imposed expectations', and they both prioritise the status quo in social arrangements in order to preserve certainty (Schwartz 1994). To the extent that conservation values are antagonistic to openness values, and are therefore, considered oppositional to innovativeness, conservation values are expected to be negatively associated with research productivity. Hence, Hypothesis $d$ is offered, that conservation values are negatively associated with research productivity.

\section{Self-transcendence values}

Universalism values and benevolence values make up the higher order values type of self-transcendence (Schwartz \& Boehnke 2004). Self-transcendence values motivate people to 'transcend selfish concerns and promote the welfare of others, close and distant, and of nature' (Schwartz \& Boehnke 2004:236).

Universalism values are defined as related to understanding, 'appreciation, tolerance and protection for the welfare of all people and for nature' and being associated with motivational goals relating to broadmindedness, wisdom, social justice, equality, a world at peace, a world of beauty, unity with nature and protection of the environment (Schwartz 1996:221). Universalism values and benevolence values are both concerned with 'enhancement of others and transcendence of selfish interests' (Schwartz 1994:25). The motivational goals associated with universalism values have an origin in, or derive from, organismic needs, or biological needs, as well as group needs such as those related to the functioning and survival of groups (Schwartz 1994). However, in the case of universalism, these group needs emerge as a response to the exposure of the individual to people outside the primary group, when intergroup interdependence is recognised and the scarcity of natural resources are also recognised (Schwartz 1994). A desire to make a contribution in research might be expected to be associated with universalism. It is tentatively suggested that universalism is positively associated with research productivity.

Benevolence values are defined as being associated with the preservation 'and enhancement of the welfare of people with whom one is in frequent personal contact', and are associated with the motivational goals of humility, acceptance of one's position in life, devotion, respect for tradition and moderation (Schwartz 1996:122). The motivational goal structure of benevolence values has its origin in (1) organismic needs, or the 'needs of individuals as biological organisms', (2) interaction needs, or the 'universal requisites of coordinated social interaction', and (3) group needs, or the 'universal requirements for smooth functioning and survival of groups' (Schwartz 1994:22). Given concern about welfare of others, and the contribution of research to society and other stakeholders, Hypothesis e is derived: that self-transcendence values are positively associated with research productivity.

\section{Gendered values effects}

Despite a long history of gender discrimination (Geisler 2000; Hassim 2006; McEwan 2000; Rogan 2013; Seidman 1993; Wood \& Jewkes 1997), in higher education contexts enrolment of women has grown faster than that of men (Bradley 2002; Pekkarinen 2012). Similarly, employment of women in South African higher education institutions has exceeded that of men (MacGregor 2009). However, given general agreement across literatures that disparate functions, roles or patterns of behaviour from men are typically imposed on women (Ridgeway \& Correll 2004), literature relating to gendered differences as to how endowments of values contribute to research productivity in this context seems scant.

Previous research from the psychoanalytic, 'role-learning, cultural feminism, and evolutionary theories of gender difference' have stressed the gender differentiation of values (Schwartz et al. 2001:534). According to these theories, men are posited to focus on 'agentic-instrumental' values, such as power, whereas women tend to stress 'expressive-communal values', such as benevolence (Schwartz et al. 2001:534). Of men and women with a higher need for power, only male respondents were found to actually manifest more competitive and aggressive behaviour, as female respondents reported having been taught more societal-oriented values (McClelland 1975). These conceptions (of agenticinstrumental and expressive-communal gender values differences) are however challenged by interactionist perspectives, which argue that no consistent gender differences are expected in values research (Schwartz et al. 2001:534). According to Schwartz et al. (2001), in the South African context, female respondents have been found to give higher priorities to tradition values $(r=0.20 ; p<0.01)$. Given this body of literature, Hypothesis $f$ is offered: that gender moderates the relationship between motivational values and research productivity. Having reviewed theory to be tested, and having derived hypotheses for testing, the methods applied in this research are now introduced. 


\section{Methodology}

This study was part of a larger project which sought to comprehensively investigate workplace relationships in the context of a large South African university. This study is premised on the assumptions of post-positivism (Cresswell 2003), which acknowledges limitations associated with a functionalist epistemological and ontological assumptions (Burrell \& Morgan 1979), but considers real mechanisms and causal channels to exist between motivational values and work productivity.

The entire institution was sampled using a comprehensive purposive sampling strategy. Although all staff were offered the opportunity to participate, refusals and non-responses were respected unconditionally, in compliance with ethics clearance stipulations. Of approximately 1300 lecturing staff, 225 usable responses were obtained, with a response rate of about $17.3 \%$. A sample size calculation was performed to ensure the sample size was sufficient to derive inferential statistics at the $5 \%$ level of significance (where a chance of Type 1 error of incorrect rejection of a true null was set equal to that of the chance of Type II error, or rejecting a false null hypothesis). Representivity was checked through comparisons by academic designation, with 46\%:32\%; $14 \%: 8 \%$ being the ratios of (1) staff without doctorates to those with doctorates without professorial designation to (2) associate professors to professors. The sample was taken to be broadly representative of the population within the institution.

\section{Measures}

The Schwartz Portrait Values Questionnaire (PVQ) was used to measure self-reported values (Schwartz 2007). This instrument has been used in over 70 countries in the world
(Data Database 2011), with consistent reliability; reliability of scale items is typically assessed in relation to the circumplex structure of values as, following Schwartz's (2007) prescriptions, the scale uses different constructs per item and the use of Cronbach's alpha measures is therefore not appropriate. Given the adequacy of design and interpretability by adults, the use of these scales for academic lecturing staff was considered appropriate. Piloting was undertaken. Exploratory factor analysis (EFA) was applied in order to understand discriminant validity (Campbell \& Fiske 1959) and to assess the broad predictions of circumplex structure in this context (Kaiser-Meyer-Olkin $=0.674$; Bartlett's sphericity test approximate Chi-squared $=1245.577$; degrees of freedom $=210$; $p<0.0001)$. The EFA loaded on seven component categories (Table 3) which was taken to broadly support the values differentiations of Schwartz's (2007) circumplex structure. A verimax rotation was applied and results are reported in Table 1. Correlations between values items were also inspected; sizes and significance of associations were taken to broadly support the circumplex structure. In testing relationships between values orientations and research productivity, on the basis of theory, certain covariate factors were included in the analysis. Gender was included in the multiple linear regression analysis as a covariate, measured as a binary variable, with male captured as 1 and female as 0 . Years as a researcher, measured in years, was also included together with the African home language variable, also measured as a binary variable. African home language was considered an important control variable due to the country's history of discrimination, which hasled tounderrepresentation of certain groups in university lecturer employment and the fact many lecturing staff do not lecture and research in their home language, which poses an additional disadvantage. Research productivity was measured as all South African Department of Higher Education accredited journal articles,

TABLE 1: Exploratory factor analysis total variance explained.

\begin{tabular}{|c|c|c|c|c|c|c|c|c|c|}
\hline \multirow[t]{2}{*}{ Component } & \multicolumn{3}{|c|}{ Initial eigenvalues } & \multicolumn{3}{|c|}{ Extraction sums of squared loadings } & \multicolumn{3}{|c|}{ Rotation sums of squared loadings } \\
\hline & Total & $\%$ of variance & Cumulative $\%$ & Total & $\%$ of variance & Cumulative $\%$ & Total & $\%$ of variance & Cumulative $\%$ \\
\hline 1 & 3.859 & 18.374 & 18.374 & 3.859 & 18.374 & 18.374 & 2.461 & 11.718 & 11.718 \\
\hline 2 & 2.286 & 10.885 & 29.259 & 2.286 & 10.885 & 29.259 & 2.296 & 10.934 & 22.652 \\
\hline 3 & 2.22 & 10.572 & 39.831 & 2.22 & 10.572 & 39.831 & 2.274 & 10.828 & 33.481 \\
\hline 4 & 1.568 & 7.468 & 47.299 & 1.568 & 7.468 & 47.299 & 1.799 & 8.569 & 42.05 \\
\hline 5 & 1.32 & 6.287 & 53.586 & 1.32 & 6.287 & 53.586 & 1.763 & 8.396 & 50.445 \\
\hline 6 & 1.111 & 5.288 & 58.874 & 1.111 & 5.288 & 58.874 & 1.545 & 7.359 & 57.805 \\
\hline 7 & 1.051 & 5.004 & 63.878 & 1.051 & 5.004 & 63.878 & 1.275 & 6.074 & 63.878 \\
\hline 8 & 0.922 & 4.389 & 68.268 & - & - & - & - & - & - \\
\hline 9 & 0.823 & 3.919 & 72.187 & - & - & - & - & - & - \\
\hline 10 & 0.778 & 3.705 & 75.892 & - & - & - & - & - & - \\
\hline 11 & 0.74 & 3.525 & 79.417 & - & - & - & - & - & - \\
\hline 12 & 0.653 & 3.111 & 82.528 & - & - & - & - & - & - \\
\hline 13 & 0.593 & 2.825 & 85.353 & - & - & - & - & - & - \\
\hline 15 & 0.492 & 2.343 & 90.352 & - & - & - & - & - & - \\
\hline 16 & 0.463 & 2.204 & 92.556 & - & - & - & - & - & - \\
\hline 17 & 0.383 & 1.824 & 94.379 & - & - & - & - & - & - \\
\hline 18 & 0.349 & 1.663 & 96.042 & - & - & - & - & - & - \\
\hline 19 & 0.328 & 1.561 & 97.603 & - & - & - & - & - & - \\
\hline 20 & 0.262 & 1.249 & 98.852 & - & - & - & - & - & - \\
\hline 21 & 0.241 & 1.148 & 100 & - & - & - & - & - & - \\
\hline
\end{tabular}


together with all conference proceedings, conference presentations, book chapters and book outputs. This was taken to be a measure of gross research productivity of an academic, representing quantity of output.

\section{Data analysis}

Data were analysed using SPSS version 23. Univariate, bivariate and multivariate analysis was applied. Particular attention was paid to assumptions of statistical testing. Spearman Rho tests of association were used; given nonnormality identified in the data, non-parametric tests of association were considered necessary. Multiple linear regression analysis was used to test associations between values dimensions and research productivity. In order to comprehensively test hypothesised gender moderation effects, path analysis using structural equation modelling (SEM) was applied. Results of testing are reported in the sections that follow.

\section{Univariate analysis and assumptions of statistical testing}

Table 2 reports measures of location, central tendency and statistical dispersion for tested variables. Median age of lecturing staff is 40 years, with women a slight majority $(53 \%)$. In order to assess normality of each variable, tests of skewness and kurtosis were applied. Given skewness and kurtosis results (Table 2) indicating non-normality, and having identified outliers in the data on the basis of univariate analysis, a decision was made to use non-parametric tests of association in the form of Spearman Rho tests. Multiple linear regression tests included tests of residuals to identify outliers and influential points. Standardised and studentised residuals, influence statistics (DFBetas and DfFits) and distance statistics (Mahalanobis, Cook's and Leverage values) were used to identify outliers and influential points. Having identified non-normal data, given Lotka's law, which predicts academic research output is skewed and very highly productive researchers tend to produce disproportionately (Lotka 1926) and might, therefore, be outliers, a decision was made to not remove these individuals from the sample but instead to apply bootstrapping to obtain bootstrapped confidence intervals against which to check results. Multiple linear regression tests applied bootstrapping at 5000 iterations.

Variance inflation factors and tolerance values as well as condition indices were checked for potential multicollinearity. The Durbin-Watson test (value $=1.99$ ) was used to check for serial correlation. Residual patterns were checked for evidence of heteroscedasticity. As an additional test to enhance scientific rigour, robust standard errors were used together with White's test for heteroscedasticity using supplementary tests with STATA. Regression residual plots were checked for patterns, and a relatively normal residual histogram plot, as well as probability-probability relationships, supported interpretation of results. This broadly suggested that if omitted variable bias was present, then the effect of these in the error term might have cancelled themselves out to some extent. Further tests of endogeneity were applied. None of the values items was found to correlate with the error term, but covariate variates were. However, no candidate variables were found to be satisfactory instruments for the three covariate items, and two-stage least squares were therefore not used. Measures of fit for the SEM testing is reported in the section on tests of gender moderation, as results are interpreted in relation to these tests.

\section{Results and discussion}

According to Spearman Rho bivariate tests of association, of the values orientations power $(-0.164 ; p<0.014)$, stimulation $(-0.134 ; p<0.045)$ and hedonism $(-0.292 ; p<0.0001)$ values were found to be negatively correlated with research output, according to Spearman Rho tests of association.

TABLE 2. Measures of location, central tendency and statistical dispersion.

\begin{tabular}{|c|c|c|c|c|c|c|}
\hline Variable & Mean/proportion & Median & Mode & Standard deviation & Skewness & Kurtosis \\
\hline Self-direction & 10.36 & 11 & 10 & 1.448 & -1.28 & 2.83 \\
\hline Power & 6.75 & 7 & 7 & 2.071 & -0.013 & -0.051 \\
\hline Universalism & 14.97 & 15 & 16 & 2.186 & -0.697 & -0.081 \\
\hline Achievement & 8.68 & 9 & 9 & 2.174 & -0.575 & -0.039 \\
\hline Security & 8.74 & 9 & 11 & 2.417 & -0.332 & -0.874 \\
\hline Stimulation & 8.15 & 8 & 10 & 2.317 & -0.274 & -0.644 \\
\hline Conformity & 7.05 & 7 & 8 & 2.346 & -0.246 & -0.453 \\
\hline Tradition & 7.77 & 8 & 7 & 2.213 & -0.111 & -0.586 \\
\hline Hedonism & 7.34 & 7 & 6 & 2.54 & -0.076 & -0.721 \\
\hline Benevolence & 9.63 & 10 & 10 & 1.55 & -0.418 & -0.174 \\
\hline $\begin{array}{l}\text { Hybrid security } \\
\text { stimulation }\end{array}$ & $0.24 \%$ & - & - & - & - & - \\
\hline $\begin{array}{l}\text { Hybrid hedonism } \\
\text { benevolence }\end{array}$ & $0.18 \%$ & - & - & - & - & - \\
\hline Age & 40.67 & 40 & $40^{\mathrm{a}}$ & 10.555 & 0.42 & -0.337 \\
\hline Gender 1 = male & $47 \%$ & - & - & - & - & - \\
\hline Years as a researcher & 10.2 & 8 & 5 & 8.842 & 1.598 & 2.789 \\
\hline Language & 0.24 & - & - & - & - & - \\
\hline English & 0.52 & - & - & - & - & - \\
\hline Research Productivity & 21.97 & 10 & 0 & 35.672 & 3.233 & 11.949 \\
\hline
\end{tabular}

a, Multiple modes exist. The smallest value is shown. 
TABLE 3. Exploratory factor analysis component matrix

\begin{tabular}{|c|c|c|c|c|c|c|c|}
\hline \multirow[t]{2}{*}{ Variable } & \multicolumn{7}{|c|}{ Component } \\
\hline & 1 & 2 & 3 & 4 & 5 & 6 & 7 \\
\hline SelfDirection1 & -0.001 & 0.280 & 0.173 & -0.038 & -0.040 & 0.403 & -0.405 \\
\hline SelfDir2 & 0.111 & 0.466 & 0.360 & 0.127 & -0.440 & -0.045 & -0.083 \\
\hline Power1 & 0.528 & 0.427 & -0.049 & 0.007 & 0.212 & -0.032 & -0.370 \\
\hline Power2 & 0.061 & 0.608 & -0.078 & -0.03 & 0.214 & -0.123 & 0.402 \\
\hline Universalism1 & -0.149 & -0.020 & 0.524 & 0.307 & -0.131 & 0.327 & -0.071 \\
\hline Univers2 & 0.104 & -0.063 & 0.759 & -0.055 & -0.015 & 0.043 & 0.046 \\
\hline Univers3 & -0.006 & -0.020 & 0.010 & 0.087 & 0.013 & 0.830 & 0.089 \\
\hline Achievement 1 & 0.187 & 0.733 & -0.117 & 0.098 & 0.079 & 0.122 & 0.053 \\
\hline Achievement2 & 0.117 & 0.799 & 0.005 & 0.174 & 0.044 & 0.073 & 0.010 \\
\hline Security 1 & -0.021 & 0.164 & 0.050 & 0.816 & 0.174 & -0.085 & -0.07 \\
\hline Security2 & 0.206 & 0.084 & -0.059 & 0.738 & 0.055 & 0.271 & 0.158 \\
\hline Stimulation1 & 0.412 & 0.111 & 0.349 & -0.016 & -0.005 & 0.465 & -0.148 \\
\hline Stim2 & 0.641 & 0.176 & 0.124 & -0.192 & -0.080 & 0.380 & -0.088 \\
\hline Conform2 & -0.074 & 0.141 & 0.183 & 0.496 & 0.569 & -0.152 & 0.126 \\
\hline Tradition1 & 0.196 & -0.202 & 0.692 & 0.233 & 0.247 & -0.161 & -0.021 \\
\hline Tradition2 & 0.145 & 0.047 & 0.125 & 0.058 & 0.719 & 0.129 & 0.172 \\
\hline Hedonism1 & 0.789 & 0.166 & 0.002 & 0.196 & 0.082 & -0.068 & 0.051 \\
\hline Hedonism2 & 0.875 & 0.029 & 0.044 & 0.042 & 0.036 & -0.031 & 0.147 \\
\hline Benevolence1 & -0.058 & 0.093 & 0.720 & -0.130 & 0.177 & 0.133 & 0.158 \\
\hline Benev2 & 0.061 & 0.264 & 0.218 & 0.082 & 0.010 & 0.072 & 0.766 \\
\hline
\end{tabular}

TABLE 4: Multiple linear regression analysis results.

\begin{tabular}{|c|c|c|c|c|c|c|c|}
\hline \multirow[t]{2}{*}{ Variable } & \multicolumn{2}{|c|}{ Unstandardised coefficients } & \multirow{2}{*}{$\frac{\text { Standardised coefficients }}{\text { Beta }}$} & \multirow[t]{2}{*}{$t$} & \multirow[t]{2}{*}{ Significance } & \multicolumn{2}{|c|}{ Collinearity statistics } \\
\hline & B & Standard error & & & & Tolerance & VIF \\
\hline (Constant) & 3.836 & 19.569 & - & 0.196 & 0.845 & - & - \\
\hline Gender ( 1 = male) & 13.114 & 3.742 & 0.184 & 3.504 & 0.001 & 0.897 & 1.115 \\
\hline Language & -7.211 & 4.261 & -0.093 & -1.692 & 0.092 & 0.815 & 1.226 \\
\hline Years as a researcher & 2.379 & 0.216 & 0.590 & 11.040 & 0 & 0.866 & 1.155 \\
\hline Self-direction & -1.776 & 1.413 & -0.072 & -1.257 & 0.210 & 0.751 & 1.332 \\
\hline Universalism & 0.933 & 0.953 & 0.057 & 0.980 & 0.328 & 0.724 & 1.381 \\
\hline Achievement & 0.577 & 1.024 & 0.035 & 0.563 & 0.574 & 0.634 & 1.576 \\
\hline Security & 2.255 & 0.872 & 0.153 & 2.585 & 0.010 & 0.707 & 1.415 \\
\hline Stimulation & 2.037 & 0.935 & 0.132 & 2.179 & 0.030 & 0.670 & 1.493 \\
\hline Conformity & -1.492 & 0.995 & -0.098 & -1.500 & 0.135 & 0.577 & 1.732 \\
\hline Tradition & -0.125 & 1.031 & -0.008 & -0.121 & 0.904 & 0.604 & 1.656 \\
\hline Hedonism & -2.309 & 0.899 & -0.164 & -2.568 & 0.011 & 0.603 & 1.659 \\
\hline
\end{tabular}

The importance of using non-parametric tests was confirmed, as parametric Pearson tests were found to report only a significant association for hedonism $(-0.257 ; p<0.0001)$. This was taken to reflect predictions of Lotka's (1926) law that highly productive researchers can be outliers across samples of researchers.

These bivariate results, however, were not considered to reflect Schwartz's (2007) theoretical structure considerations, and it was considered appropriate to include their variance together and include control variables to obtain net multivariate effects over and above the variance of other variables in the equation. The following specification was therefore tested.

$$
\begin{aligned}
R P R= & \alpha_{i}+\beta_{1} S D+\beta_{2} P W+\beta_{3} U N I+\beta_{4} A C H+\beta_{5} S E C+\beta_{6} S T M \\
& +\beta_{7} C F M+\beta_{8} T D+\beta_{9} H E D+\beta_{10} B E N+\beta_{11} G E N+\beta_{12} L N G \\
& +\beta_{13} E X P+e
\end{aligned}
$$

According to this specification, research productivity $(R P R)$ is regressed against self-direction $(S D)$, power $(P W)$, universalism (UNI), achievement $(A C H)$, security $(S E C)$, stimulation (STM), conformity (CFM), tradition (TD), hedonism (HED), benevolence $(B E N)$, gender $(G E N)$, language $(L N G)$ and years of experience as a researcher $(E X P)$.

Results of testing (Table 4) indicate security and stimulation values to be positively associated with research productivity and hedonism and benevolence to be positively associated. Results were confirmed by bootstrapped confidence intervals (Table 5). The presence of both negative and positive associations for values items challenge longstanding theory predicting values systems are fundamentally a constraint to convergence of knowledge across contexts (Kerr 1983; Rowley \& Benson 2002) and support arguments for potential positive influences of values on research performance in the same way as other behaviours (Schwartz 2007). The model, with an adjusted $R$-squared value of 0.447 , suggested almost 
TABLE 5: Bootstrapped standard errors and confidence intervals.

\begin{tabular}{|c|c|c|c|c|c|c|}
\hline \multirow[t]{2}{*}{ Variable } & \multirow{2}{*}{$\begin{array}{l}\text { Unstandardised } \\
\text { coefficients }\end{array}$} & \multicolumn{2}{|c|}{ Bootstrap } & \multirow[t]{2}{*}{ Sig. (two-tailed) } & \multicolumn{2}{|c|}{$95 \%$ confidence interval } \\
\hline & & Bias & Standard error & & Lower & Upper \\
\hline (Constant) & 3.836 & 0.867 & 17.166 & 0.823 & -28.223 & 39.685 \\
\hline Gender ( 1 = male) & 13.114 & -0.133 & 4.061 & 0.003 & 5.983 & 20.803 \\
\hline Years as a researcher & 2.379 & -0.014 & 0.339 & 0 & 1.755 & 2.992 \\
\hline Language & -7.211 & 0.078 & 2.995 & 0.020 & -13.612 & -1.097 \\
\hline Self-direction & -1.776 & -0.079 & 1.465 & 0.224 & -4.611 & 0.792 \\
\hline Power & 0.764 & 0.027 & 1.287 & 0.567 & -1.416 & 3.424 \\
\hline Universalism & 0.933 & 0.019 & 0.991 & 0.345 & -1.164 & 2.928 \\
\hline Achievement & 0.577 & -0.033 & 0.971 & 0.556 & -1.463 & 2.320 \\
\hline Security & 2.255 & -0.025 & 1.113 & 0.047 & 0.260 & 4.421 \\
\hline Stimulation & 2.037 & 0.019 & 0.934 & 0.034 & 0.316 & 4.027 \\
\hline Conformity & -1.492 & -0.019 & 1.179 & 0.219 & -4.103 & 0.706 \\
\hline Tradition & -0.125 & 0.010 & 0.858 & 0.879 & -1.828 & 1.595 \\
\hline Hedonism & -2.309 & -0.038 & 0.951 & 0.018 & -4.339 & -0.649 \\
\hline
\end{tabular}

Bootstrap results are based on 5000 bootstrap samples.

half the variance in research productivity was explained by the model (standard error of estimate $=26.535$ ).

The change in sign of stimulation from negative to positive once tested within a model with covariates is noted. Given stimulation values represent excitement, novelty and challenge in life (Schwartz \& Boehnke 2004) and are related to motivational goals associated with being daring and having a varied and exciting life (Schwartz 1996:122), these values are associated with goals that derive from the individual needs of individuals as biological organisms. This differs from values that derive from the requirements of coordinated social interaction or the smooth functioning and survival of groups (Schwartz 1994). Stimulation values, together with hedonism values, are therefore the only values that have a biological origin, with no interaction or group source for the goals of these values (Schwartz 1994). To the extent that stimulation is associated with innovativeness, this multivariate finding suggests highly productive research output might be motivated by a biological dimension of excitement which is linked to innovativeness. However, a caveat is required; given the SEM model failed to support this significant association and given the opposite sign in multivariate testing using covariates, this result is considered inconsistent, and to the extent that stimulation is an openness to change value, Hypothesis a, that openness to change values are positively associated with research productivity, is not considered supported and the null is not rejected.

The significance of security values, however, suggest a dichotomy in the significance of both openness to change and conservation higher order values, as Schwartz's (2007) theory predicts these are values in opposition to each other. Security needs relate to safety, 'harmony and stability of society, of relationships, and of self', and are associated with motivational goals related to family security, social order, cleanliness and the reciprocation of favours (Schwartz 1996:221). Motivational goals of security values are derived from organismic needs, or of individuals as biological organisms, interaction needs, or the universal requisites of coordinated social interaction, and group needs, or the 'universal requirements for smooth functioning and survival of groups' (Schwartz 1994:22).

The significance of this result in multivariate testing suggests high research productivity might therefore also be associated with motivational values of safety and security. It is possible that individuals experiencing insecurity in this context might strive for high output due to higher endowments of security values, which relate to safety and security. However, as these values are considered antithetical to the innovative values of openness to change, the significance of this association is perhaps paradoxical. It is possible individuals more sensitive to, or who feel more vulnerable to, current social unrest or other organisational and societal occurrences (as expected of individuals with high security values endowments) may react to this by being more research productive. Violence is not uncommon to this context, as service delivery protests and student protests on university campuses, in a societal context of high, and typically racialised, inequality, reflect the conditions of the country's past (Laccino 2015). This climate of uncertainty might have a disproportionate influence on individuals with high security values needs. This research, however, is not causal, and no claim is made here that a subset of researchers is more productive due to their heightened values sensitivity to contextual uncertainty and lack of perceived societal, family or personal safety. However, it is difficult to explain this finding as, according to Schwartz (2007), security values are not inherently innovative and would be expected to be negatively associated with research productivity.

The South African context has however been identified as having different, or atypical, respondent responses on the security values items. Schwartz et al. (2001:528), also using the PVQ items, found security values to be located in the selftranscendence higher order region of values structure, which may have reflected 'sensitivity of value structures to powerful historical events', although the values structure overall was relatively representative of other contexts. Given this result, for Hypothesis d, that conservation values are negatively associated with research productivity, the null hypothesis is not rejected. 
Hypothesis $a$ and Hypothesis $d$ are dealt with together here because they are theoretically antagonistic and their results suggest a paradox according to Schwartz's (1992) theoretical predictions. These findings warranted further testing, and values scores were dichotomised above the median to represent individuals high in stimulation and conservation values. This provided a test of the extent to which individuals with high endowments of stimulation values also have high security values, or who were 'hybrids', and almost a quarter ( $24 \%$ ) of the sample were found to fall into this category. The two values items were however not correlated (Spearman Rho $=0.081 ; p<0.229)$, supporting the predicted theoretical distance between them. Further research might offer more insight into these relationships.

Hedonism values are adjacent in the structure of values to stimulation values, and are associated with pleasure, 'sensuous gratification for oneself' and motivational goals of pleasure and the enjoyment of life (Schwartz 1996:122). Whereas stimulation values are associated with openness to experience, hedonism values are associated with selfenhancement, although both share a 'desire for affectively pleasant arousal' (Schwartz 1994:24) related to needs of individuals as biological organisms, rather than requirements of coordinated social interaction or the smooth functioning and survival of groups (Schwartz 1994). Individuals who are able to subordinate biologically oriented goal-related values such as hedonism to work tasks that are relatively 'less pleasurable' are expected to have a greater tolerance for work that might offer less immediate gratification. If research work is less 'pleasurable' than other tasks, it is expected that hedonism values are negatively related to research productivity. This notion is supported by the negative association found for hedonism with research productivity, and for Hypothesis $c$, that self-enhancement values are negatively associated with research productivity, the null hypothesis is rejected.

Security and benevolence values are the only two values orientations that derive from all three types of origins: biological, interaction and coordinated social interaction needs (Schwartz 1994). It is notable that the two values with only biological origins (stimulation and hedonism) were found to be significantly associated with research productivity together with the two values (security and benevolence) with all three origins, but with opposite signs in each instance. Benevolence values, associated with preservation and enhancement of 'the welfare of people with whom one is in frequent personal contact', are related to motivational goals of humility, acceptance of one's position in life, devotion, respect for tradition and moderation (Schwartz 1996:122). Given concern for welfare of others, and the contribution of research to society and other stakeholders expected for these values, the negative association between benevolence values and research productivity is unexpected, and for Hypothesis e, that self-transcendence values are negatively associated with research productivity, the null hypothesis is not rejected. Given hedonism and benevolence values are oppositional values, hybrids were also identified for these values, and these were found to comprise $18 \%$ of the sample. It is tentatively suggested here that these individuals might be less productive in research because of a preference for teaching over research, as the point biserial correlation between hybrid membership and deriving primary job satisfaction from teaching is significant (Spearman Rho $=0.38 ; p<0.0001$ ), yet not significant for research. This might suggest contribution and stimulation offered by teaching may offer more proximal payoffs for these motivational values than research. However, without a causal design, this is merely a suggested explanation, and further research might offer more insight into these relationships.

In order to test the hypothesis that gender moderates the relationship between motivational values and research productivity, an SEM model was used, and tests of path differences applied. The SEM model fit statistics are shown in Table 6a-f.

The CMIN/DF, or minimum discrepancy ratio, of 3.236 was less than the cutoff of 5 representing poor mode fit. In terms

TABLE 6a: SEM model fit statistics.

\begin{tabular}{|c|c|c|c|c|c|}
\hline Model & Number of parameters & Chi-square & Degrees of freedom & Significance & Minimum discrepancy \\
\hline Default model & 190 & 58.255 & 18 & 0 & 3.236 \\
\hline Saturated model & 208 & 0 & 0 & - & - \\
\hline Independence model & 52 & 746.613 & 156 & 0 & 4.786 \\
\hline
\end{tabular}

SEM, structural equation modelling.

TABLE 6b: SEM model fit statistics.

\begin{tabular}{|c|c|c|c|c|c|}
\hline Model & Normed fit index (Delta1) & Relative fit index (rho1) & Incremental fit index (Delta2) & Tucker-Lewis index (rho2) & Comparative fit index \\
\hline Default model & 0.922 & 0.324 & 0.945 & 0.409 & 0.932 \\
\hline Saturated model & 1 & - & 1 & - & 1 \\
\hline Independence model & 0 & 0 & 0 & 0 & 0 \\
\hline
\end{tabular}

SEM, structural equation modelling.

TABLE 6c: SEM model fit statistics.

\begin{tabular}{lccc}
\hline Model & Root mean square error & Low limit 90 & High limit 90 \\
\hline Default model & 0.10 & 0.072 & 0.129 \\
Independence model & 0.13 & 0.121 & 0.002 \\
\hline
\end{tabular}

SEM, structural equation modelling. 
TABLE 6d: SEM model fit statistics.

\begin{tabular}{lcc}
\hline Model & $\begin{array}{c}\text { Akaike information } \\
\text { criterion }\end{array}$ & Browne-Cudeck criterion \\
\hline Default model & 438.255 & 493.078 \\
Saturated model & 416.000 & 476.017 \\
Independence model & 850.613 & 865.618 \\
\hline
\end{tabular}

SEM, structural equation modelling.

TABLE 6e: SEM model fit statistics.

\begin{tabular}{lcccc}
\hline Model & $\begin{array}{c}\text { Expected cross- } \\
\text { validation index }\end{array}$ & $\begin{array}{c}\text { Low } \\
\text { limit 90 }\end{array}$ & $\begin{array}{c}\text { High } \\
\text { limit 90 }\end{array}$ & $\begin{array}{c}\text { Modified cross- } \\
\text { validation index }\end{array}$ \\
\hline Default model & 1.965 & 1.878 & 2.086 & 2.211 \\
$\begin{array}{l}\text { Saturated } \\
\text { model }\end{array}$ & 1.865 & 1.865 & 1.865 & 2.135 \\
$\begin{array}{l}\text { Independence } \\
\text { model }\end{array}$ & 3.814 & 3.45 & 4.213 & 3.882 \\
\hline
\end{tabular}

SEM, structural equation modelling.

TABLE 6f: SEM model fit statistics.

\begin{tabular}{lcc}
\hline Model & HOELTER (0.05) & HOELTER (0.01) \\
\hline Default model & 112 & 135 \\
Independence model & 57 & 61 \\
\hline
\end{tabular}

SEM, structural equation modelling.

of baseline comparison, or relative fit tests, the normed fit index (NFI), comparative fit index (CFI, a measure of complete covariation in the data, as is the NFI but adjusted for sample size) and incremental fit index (which takes into account degrees of freedom) have values above 0.9 , which represent a reasonably good fit (Byrne 2010). Relative fit index (RFI) and Tucker-Lewis index (TLI) values, however, fall short of this. The root mean square error of approximation (RMSEA) value is 0.1 , which is in excess of the 0.8 regarded generally as reasonable fit (Browne \& Cudeck 1993), and confidence intervals suggest confidence in this value (Byrne 2010).

Tests for parsimony in model fit were performed, which take numbers of parameters into account. These tests included the Akaike information criterion (AIC), consistent Akaike information criterion (CAIC), Browne-Cudeck criterion (BCC) and Bayes information criterion (BIC). Results revealed values smaller than those of the independence model and a little greater than those of the saturated models. The smaller the model's values in relation to independence and saturated models, the more reasonable the parsimony of model fit (Byrne 2010).

The expected cross-validation index (ECVI) value for the model is less than that of the independence model but larger than that for the saturated model, and confidence intervals suggest accuracy for the value; the modified cross-validation index (MECVI), which reflects BCC value adjusted for scale factor, is also substantially lower than that for the independence model but more than the saturated model. The HOELTER 0.01 value is below 200; this, together with the other fit statistics discussed, despite adequate fit in some areas, is poor in others. However, guided by the theoretical rationale (Byrne 2010), these fit indicators are taken to have lower fit for the reason that the model fit statistics relate to the complete model, yet differences in path significance between the male and female models meant paths could not be trimmed to increase the fit of the model. For the male sample, Mardia's coefficient of multivariate normality was 10.67 and for the female sample 28.688. Bootstrapped confidence levels were therefore used to check significance of findings.

The male model, with security positively $(3.267 ; p<0.018)$ and hedonism negatively $(-2.774 ; p<0.027)$ associated with research productivity, and the female model, with benevolence negatively associated with research productivity $(-2.863 ; p<0.021)$, therefore differed from each other in significance of paths. This was however considered insufficient evidence to assume gender moderation due to the potential for range restriction. Range restriction in either sample, for example, might render a path in one sample nonsignificant, and the differences between paths can result from differences in variance and not true differences due to gender. It was expected that the use of chi-squared difference tests supplemented by critical ratio tests might provide a more valid test of gender moderation.

Chi-squared difference tests were run for the model. Given the chi-squared values of 58.255 (18 degrees of freedom) for the unconstrained model and 122.792 (44 degrees of freedom) for the fully constrained model, these groups were found to be different at the model level, supporting the possibility of differences by paths. Paths for each of the values orientations to research output were constrained on a one-to-one basis. Security was found to differ by gender $(p<0.05)$ according to the chi-squared difference tests: for men, security values are more strongly associated with research output. This was confirmed by a test using the critical ratios method (Table 7). This finding supports the differentiation used by Schwartz (2007) in the construction of the PVQ, which uses female comparisons for women and male comparisons for men in questions posed to respondents. It is possible this result reflects gender differences in agenticinstrumental values (Schwartz et al. 2001), as security values may be more salient for men.

The relationship between years as a researcher and research productivity is also stronger for men (gender also moderates this relationship significantly). In terms of temporal effects, years of experience as a researcher is negatively associated with stimulation values for women, but not for men (another moderated relationship). It is possible these effects are associated with gender differences in expressive-communal values, which is a primary axis of gender values difference (Schwartz et al. 2001). If research is inherently more agenticinstrumental and less expressive-communal in nature (as teaching might be), then years of experience as a researcher might be expected to differ in its influence, as these findings suggest. The gender differentiation of samples might shed light on the non-significance of stimulation in the SEM model. Given these results, Hypothesis $f$, that gender moderates the relationship between motivational values and research productivity is taken to be supported and the null hypothesis is rejected.

The finding that gender moderates the relationship between security values and research productivity in this context 
TABLE 7: Critical ratio tests of path differences by gender.

\begin{tabular}{|c|c|c|c|c|c|c|c|}
\hline \multirow{2}{*}{$\begin{array}{l}\text { Outcome } \\
\text { variable }\end{array}$} & & \multirow{2}{*}{$\begin{array}{l}\text { Independent } \\
\text { variable }\end{array}$} & \multicolumn{2}{|c|}{ Male } & \multicolumn{2}{|c|}{ Female } & \multirow[t]{2}{*}{ z-stat } \\
\hline & & & Estimate & $\boldsymbol{P}$ & Estimate & $\boldsymbol{P}$ & \\
\hline Benevolence & $\leftarrow$ & Language & 0.445 & 0.158 & 0.390 & 0.247 & -0.120 \\
\hline Hedonism & $\leftarrow$ & Language & -0.375 & 0.410 & 1.088 & 0.057 & $2.003^{* *}$ \\
\hline Security & $\leftarrow$ & Language & 1.395 & 0.001 & 1.707 & 0.002 & 0.445 \\
\hline Universalism & $\leftarrow$ & Language & 1.227 & 0.006 & -0.585 & 0.187 & $-2.877 * * *$ \\
\hline Benevolence & $\leftarrow$ & Years as a researcher & -0.003 & 0.833 & 0.013 & 0.452 & 0.694 \\
\hline Security & $\leftarrow$ & Years as a researcher & -0.004 & 0.873 & -0.028 & 0.332 & -0.674 \\
\hline Universalism & $\leftarrow$ & Years as a researcher & 0.023 & 0.327 & 0.008 & 0.715 & -0.438 \\
\hline Research Productivity & $\leftarrow$ & Years as a researcher & 2.998 & 0.000 & 1.227 & 0.000 & $-4.597 * * *$ \\
\hline Research Productivity & $\leftarrow$ & Language & -17.119 & 0.007 & 0.939 & 0.824 & $2.369 * *$ \\
\hline Research Productivity & $\leftarrow$ & Universalism & 0.990 & 0.471 & 1.697 & 0.046 & 0.437 \\
\hline Research Productivity & $\leftarrow$ & Security & 3.267 & 0.020 & 0.099 & 0.883 & $-2.034 * *$ \\
\hline Research Productivity & $\leftarrow$ & Hedonism & -2.774 & 0.029 & -0.735 & 0.263 & 1.425 \\
\hline Self- Direction & $\leftarrow$ & Years as a researcher & 0.002 & 0.849 & -0.010 & 0.617 & -0.528 \\
\hline Power & $\leftarrow$ & Years as a researcher & -0.027 & 0.199 & -0.041 & 0.079 & -0.441 \\
\hline Achievement & $\leftarrow$ & Years as a researcher & -0.005 & 0.820 & -0.039 & 0.133 & -1.023 \\
\hline Stimulation & $\leftarrow$ & Years as a researcher & -0.016 & 0.463 & -0.090 & 0.000 & $-2.082 * *$ \\
\hline Conformity & $\leftarrow$ & Years as a researcher & 0.012 & 0.593 & -0.020 & 0.476 & -0.891 \\
\hline Tradition & $\leftarrow$ & Years as a researcher & 0.021 & 0.310 & -0.006 & 0.811 & -0.811 \\
\hline Self- Direction & $\leftarrow$ & Language & 0.351 & 0.120 & 0.199 & 0.606 & -0.338 \\
\hline Power & $\leftarrow$ & Language & -0.604 & 0.140 & 0.666 & 0.141 & $2.084 * *$ \\
\hline Achievement & $\leftarrow$ & Language & -0.434 & 0.293 & 0.607 & 0.232 & 1.592 \\
\hline Stimulation & $\leftarrow$ & Language & -0.179 & 0.681 & 0.300 & 0.570 & 0.699 \\
\hline Conformity & $\leftarrow$ & Language & 1.191 & 0.007 & 0.977 & 0.077 & -0.303 \\
\hline Tradition & $\leftarrow$ & Language & 1.966 & 0.000 & 0.110 & 0.827 & $-2.898 * * *$ \\
\hline
\end{tabular}

$*, p<0.10 ; * *, p<0.05 ; * * *, p<0.01$.

suggests this relationship is only significant for men. This has implications for the findings discussed previously. Notwithstanding potential differences along the agenticinstrumental versus expressive-communal values axis (Schwartz et al. 2001), if men (but not women) who feel especially vulnerable to uncertainty or threats to safety and security in this context work significantly more productively to produce higher research output, the question arises: why? Why is it that men with security values react in a way different to women? Causal investigations, however, were beyond the scope delimitations of this work, and it is left to further research to uncover the causal channels or mechanisms underlying these effects. Nevertheless, these findings are considered important as they provide the basis for such further research and have identified what could be an important dimension of the relationship between research productivity, job performance and motivational values in this context.

\section{Implications for human resource management and further research}

To date, little has been written in the human resource management literature on the heterogeneity of academic staff values in the contemporary South African context. The findings of this research suggest important differences in academic motivational values, which might imply a targeted management approach to supporting highly productive research staff. The following implications derive from the analysis.
Firstly, given that highly productive research staff are typically not remunerated for marginal increases in productivity, private sector remuneration models (Bussin \& Modau 2015) cannot operate in the same way in the academic context, so supporting highly productive researchers according to their motivational values, endowments might be useful. In this light, given the higher levels of security values of highly productive researchers, managing staff perceptions of uncertainty, safety and security might be associated with improved retention (Smit et al. 2015; Takawira et al. 2014), well-being and job satisfaction (Hansen et al. 2015) for these individuals, particularly men.

South African academics and research into local challenges can help to solve the country's problems, as its businesses and organisations face threats of business failure (Pretorius 2008), skills shortages, infrastructure backlogs and other challenges that constrain country growth (Stanz 2009). In particular, entrepreneurship education (Pretorius, Nieman \& van Vuuren 2005) can be key to solving problems of high youth unemployment (Mtembu \& Govender 2015; Oluwajodu et al. 2015). But key to this is the need to develop and retain highly productive researchers and management needs to support them in this context, lest they are lost to a global market for academic skills. Further research into motivations of academics will need to offer more specific knowledge of how to better match employment support to individual values motivations. Providing a safe and secure environment for academics amidst sometimes violent campus and societal protest within a society beset by high 
inequality and political uncertainty (Laccino 2015) is perhaps a good place to start.

Individuals with higher endowments of hedonism and benevolence values, which can co-occur (about one in five in this sample), might be associated with primary job satisfaction derived from teaching, and may be less research productive. However, these staff might benefit from support tailored to their intrinsic values orientations; introducing a tutor track or a career track that rewards teaching at the same level as research might be more appropriate for individuals with these values motivations.

Secondly, given seminal concerns that academic research is not inherently sufficiently innovative (Kuhn 1970; Lakatos 1970), lack of significance of the self-direction values orientation representing innovativeness raises a concern, as innovativeness was expected to dominate in associations with research productivity. Management theorists might do well to investigate this further, and managers in academic contexts might also benefit from an assessment of the extent to which research outputs are inherently innovative. In the South African context where research ratings and numbers of publications are used to frame 'success' of academics, there is perhaps a risk the system becomes more of a 'numbers game' rather than a genuine quest to discover new knowledge.

\section{Conclusions}

The objective of this research was to test theory relating motivational values to research productivity and to test the extent to which these relationships are gendered. The core theoretical tension addressed in this study was firstly that theory predicted that academic research was expected to be inherently innovative, and therefore that testing would reflect a relationship between innovative values and research productivity. However, this was not so and, instead, a relationship between security values and research productivity was found, casting doubt on theory predicting the dominance of innovative values in research production. It was further found that gender moderates this relationship: it is stronger for men. Tested relationships around security values were found to reflect previous research in South Africa, which found security values to load atypically within the Schwartz circumplex values structure. In a national context of societal protest and uncertainty across academic institutions, it was concluded that this environment might be especially problematic for individuals with higher security motivational values endowments, who typically produce higher levels of research output.

The second theoretical tension addressed was that theory predicted self-transcendent values, or those associated with a prioritisation of the common good, would be motivationally related to production of research. However, benevolence values were found to be negatively associated with research productivity, together with hedonism values. It was found that individuals with high endowments of both benevolence and hedonism reported deriving their primary job satisfaction from teaching and not research. It is concluded that these findings challenge certain assumptions of theory, and that academics are not necessarily motivated by the common good, or by innovative values in this context. It is hoped that further research is able to unravel the causal connections between these relationships, even if it (as in the case of this research) provokes more questions than those it sets out to answer.

Given only about $56 \%$ of study respondent academics were from South Africa, almost half of the institution's academics might be considered international staff. The global interconnectedness of academic staff makes the findings of this study salient for other contexts, to the extent that they share characteristics with the one under study. Arguably, certain characteristics are shared with the global academic context, and further research might usefully extend the work of this research to establish to what extent these findings are common to other international contexts.

\section{Acknowledgements Competing interests}

The author declares that he has no financial or personal relationships that may have inappropriately influenced him in writing this article.

\section{References}

Botha, D. \& Cronjé, F., 2015, 'Occupational health and safety considerations for women employed in core mining positions', South African Journal of Human Resource Management 13(1), 1-12. https://doi.org/10.4102/sajhrm.v13i1.652

Bradley, K., 2002, 'Gender inequality', in D. Levinson, P.W. Cookson \& A.R. Sadovnik (eds.), Education and sociology, pp. 295-300, Taylor and Francis, New York.

Browne, M.W. \& Cudeck, R., 1993, 'Alternative ways of assessing model fit', in K.A. Bollen \& J.S. Long (eds.), Testing structural equation models, pp. 136-162, SAGE, Beverly Hills, CA.

Burrell, G. \& Morgan, G., 1979, Sociological paradigms and organisational analysis, Heinemann, London.

Bussin, M. \& Modau, M.F., 2015, 'The relationship between Chief Executive Officer Remuneration and financial performance in South Africa between 2006 and 2012', South African Journal of Human Resource Management 13(1), 1-18. https://doi.org/10.4102/sajhrm.v13i1.668

Byrne, B.M., 2010, Structural equation modeling with Amos: Basic concepts, applications, and programming, 2nd edn., Taylor and Francis Group, New York.

Callaghan, C.W., 2013, 'Psychological GLOBE organizational culture values and research productivity', Academy of Management Conference, Johannesburg, South Africa, January 7-10.

Callaghan, C.W., 2015, 'Designation differences and academic career progression', Acta Commercii 15(1), 1-12. https://doi.org/10.4102/ac.v15i1.267

Callaghan, C.W., 2016, "Publish or perish": Family life and academic research productivity', South African Journal of Human Resource Management 14(1), 1-9. https://doi.org/10.4102/sajhrm.v14i1.727

Campbell, D.T. \& Fiske, D.W., 1959, 'Convergent and discriminant validation by the multitrait-multimethod matrix', Psychological Bulletin 56, 81-105. https://doi. org/10.1037/h0046016

Chinyamurindi, W.T., 2016, 'A narrative investigation into the meaning and experience of career success: Perspectives from women participants', South African Journal of Human Resource Management 14(1), 1-11. https://doi.org/10.4102/sajhrm. v14i1.659

Coetzee, M., Ferreira, N. \& Potgieter, I.L., 2015, 'Assessing employability capacities and career adaptability in a sample of human resource professionals', South African Journal of Human Resource Management 13(1), 1-9. https://doi. org/10.4102/sajhrm.v13i1.682

Cresswell, J.W., 2003, Research design. Qualitative, quantitative and mixed methods approaches, 2nd edn., SAGE, Thousand Oaks, CA.

Data Database, 2011, ESS Human Values Scale/Portrait Values Questionnaire, viewed 12 July 2012, from http://datadatabase.files.wordpress.com/2011/03/schwartzvalue-inventory.pdf

Geisler, G., 2000, 'Women, men and politics in South Africa', The Journal of Modern African Studies 38(4), 605-630. https://doi.org/10.1017/S0022278X00003372 
Hansen, A., Buitendach, J.H. \& Kanengoni, H., 2015, 'Psychological capital, subjective well-being, burnout and job satisfaction amongst educators in the Umlazi region in South Africa', South African Journal of Human Resource Management 13(1) in South Africa', South African Journal of Human

Hassim, S., 2006, Women's organizations and democracy in South Africa: Contesting authority, University of Wisconsin Press, Madison, WI.

Hofstede, G., 1980, Culture's consequences: International differences in work-related values, SAGE, Beverly Hills, CA.

House, R.J., Hanges, P.J., Javidan, M., Dorfman, P.W. \& Gupta, V. (eds.), 2004, Culture leadership and organizations: The GLOBE study of 62 societies, SAGE, Thousand Oaks, CA.

Kerr, C., 1983, The future of industrial societies: Convergence of continuing diversity? Harvard University Press, Cambridge.

Kuhn, T.S., 1970, The structure of scientific revolutions, 2nd edn., University of Chicago Press, Chicago, IL.

Laccino, L., 2015, Fees must fall protest as it happened: South African students violently clash with police, viewed 23 May 2016, from http://www.ibtimes.co.uk/ south-africa-fees-must-fall-student-protest-turns-violent-attack-policejournalists-1525361

Lakatos, I., 1970, 'Falsification and the methodology of scientific research programmes', in I. Lakatos \& A. Musgrave (eds.), Criticism and the growth of knowledge, Cambridge University Press, Cambridge.

Latour, B., 2000, 'When things strike back: A possible contribution of "science studies" to the social sciences', British Journal of Sociology 51(1), 107-123. https://doi. org/10.1080/000713100358453

Lewis, M.W. \& Grimes, A.J., 1999, 'Metatriangulation: Building theory from multiple paradigms', Academy of Management Review 24(4), 672-690.

Lotka, A.J., 1926, 'The frequency distribution of scientific productivity', Journal of the Washington Academy of Sciences 16, 317

MacGregor, K., 2009, 'South Africa: Gender divide breached', University World News, viewed 28 April 2013, from http://www.universityworldnews.com/article. php?story=20091023110723502

Makhuzeni, B. \& Barkhuizen, E.N., 2015, 'The effect of a total rewards strategy on school teachers' retention', South African Journal of Human Resource Management 13(1), 1-10. https://doi.org/10.4102/sajhrm.v13i1.699

Massie, K., Collier, D. \& Crotty, A., 2014, Review of executive salaries in South Africa Johannesburg: Jacana media, Johannesburg.

McClelland, D., 1961, The achieving society, Van Nostrand, Princeton, NJ.

McClelland, D., 1975, Power the inner experience, Irvington, New York.

McEwan, C., 2000, 'Engendering citizenship: Gendered spaces of democracy in South Africa', Political Geography 19(5), 627-651. https://doi.org/10.1016/S0962 6298(00)00009-3

Mtembu, V.N. \& Govender, L.N., 2015, 'Perceptions of employers and unemployed youth on the proposed youth employment wage subsidy incentive in South Africa: A KwaZulu-Natal study', South African Journal of Human Resource Management 13(1), 1-9. https://doi.org/10.4102/sajhrm.v13i1.653

Oluwajodu, F., Blaauw, D., Greyling, L. \& Kleynhans, E.P.J., 2015, 'Graduate unemployment in South Africa: Perspectives from the banking sector', South African Journal of Human Resource Management 13(1), 1-9. https://doi. org/10.4102/sajhrm.v13i1.656

Pekkarinen, T., 2012, Gender differences in education, viewed 2 December 2013, from http://ftp.iza.org/dp6390

Pretorius, M., 2008, 'Critical variables of business failure: A review and classification framework', South African Journal of Economic and Management Sciences 11(4), 408-430.

Pretorius, M., Nieman, G. \& Van Vuuren, J., 2005, 'Critical evaluation of two models for entrepreneurial education: An improved model through integration', International Journal of Educational Management 19(5), 413-427. https://doi. org/10.1108/09513540510607743
Ridgeway, C.L. \& Correll, S.J., 2004, 'Unpacking the gender system. A theoretical perspective on gender beliefs and social relations', Gender and Society 18(4), 510-531. https://doi.org/10.1177/0891243204265269

Rogan, M., 2013, 'Alternative definitions of headship and the "feminisation" of income poverty in post-apartheid South Africa', Journal of Development Studies 49(10), 1344-1357. https://doi.org/10.1080/00220388.2013.812199

Rokeach, M. \& Ball-Rokeach, S.J., 1989, 'Stability and change in American value priorities, 1968-1981', American Psychologist 44(5), 775-784. https://doi. org/10.1037/0003-066X.44.5.775

Ross, M., Schwartz, S.H. \& Surkiss, S., 1999, 'Cultural value differences: Some implications for work', Applied Psychology: An International Review 48, 23-47. https://doi.org/10.1111/j.1464-0597.1999.tb00047.x

Rowley, C. \& Benson, J., 2002, 'Convergence and divergence in Asian human resources management', California Management Review 44(2), 90-109. https://doi. org/10.2307/41166124

Schutte, N., Barkhuizen, N. \& Van der Sluis, L., 2015, 'Exploring the current application of professional competencies in human resource management in the South African context', South African Journal of Human Resource Management 13(1), 1-9. https://doi.org/10.4102/sajhrm.v13i1.724

Schwartz, S., 1994, 'Are there universal aspects in the structure and contents of human values', Journal of Social Issues 50(4), 19-45. https://doi.org/10.1111/j. 1540-4560.1994.tb01196.x

Schwartz, S., 1996, Value priorities and behavior: Applying a theory of integrated value systems, viewed 31 April 2012, from http://www.palermo.edu/ value systems, viewed 31 April 2012, from http://W
cienciassociales/publicaciones/pdf/Psico2/2Psico\%2007.pdf

Schwartz, S.H., 1992, 'Universals in the content and structure of values: Theory and empirical tests in 20 countries', in M. Zanna (ed.), Advances in experimental and social psychology, vol. 25, pp. 1-65, Academic Press, New York.

Schwartz, S.H., 2007, Chapter 7, A proposal for measuring orientations across nations, viewed 12 July 2012, from http://www.europeansocialsurvey.org/index. php?option $=$ com_docmanandtask $=$ doc_viewandgid $=126$ and ltemid $=80$

Schwartz, S.H. \& Bardi, A., 2001, 'Value hierarchies across cultures: Taking a similarities perspective', The Journal of Cross Cultural Psychology 18, 385-410.

Schwartz, S.H. \& Boehnke, K., 2004, 'Evaluating the structure of human values with confirmatory factor analysis', Journal of Research in Personality 38, 230-255. https://doi.org/10.1016/S0092-6566(03)00069-2

Schwartz, S.H., Melech, G., Lehmann, A., Burgess, S., Harris, M. \& Owens, V.S., 2001 'Extending the cross-cultural validity of the theory of basic human values with different method of measurement', Journal of Cross-Cultural Psychology 32(5), 519-542. https://doi.org/10.1177/0022022101032005001

Seidman, G.W., 1993, 'No freedom without the women: Mobilisation and gender in South Africa, 1970-1992', Signs 18(2), 291-320. https://doi.org/10.1086/494794

Smit, W., Stanz, K. \& Bussin, M., 2015, 'Retention preferences and the relationship between total rewards, perceived organisational support and perceived supervisor support', South African Journal of Human Resource Management 13(1), 1-13. https://doi.org/10.4102/sajhrm.v13i1.665

Stanz, K., 2009, Factors affecting employee retention: What do engineers think? Management Today, 17-19, viewed 23 May 2016, from http://repository.up.ac. za/dspace/bitstream/handle/2263/12199/Stanz_Factors\%282009\%29. pdf? sequence $=1$ andisAllowed $=\mathrm{y}$

Takawira, N., Coetzee, M. \& Schreuder, D., 2014, 'Job embeddedness, work engagement and turnover intention of staff in a higher education institution: An exploratory study', South African Journal of Human Resource Management 12(1) 1-10. https://doi.org/10.4102/sajhrm.v12i1.524

Willmott, H., 1993, 'Breaking the paradigm mentality', Organization Studies 14(5), 681-719. https://doi.org/10.1177/017084069301400504

Winter, D.G., 1973, The power motive, The Free Press, New York.

Wood, K. \& Jewkes, R., 1997, 'Violence, rape, and sexual coercion: Everyday love in a South African Township', Gender and Development 5(2), 41-46. https://doi. org/10.1080/741922353 